\title{
Perdas Endógenas e Coeficientes de Absorção Aparente e Real do Magnésio em Caprinos $^{1}$
}

\author{
Claudete Regina Alcalde ${ }^{2}$, Jane Maria Bertocco Ezequiel ${ }^{3}$, Adriana da Cruz França Lema ${ }^{2}$, \\ Euclides Braga Malheiros ${ }^{4}$
}

RESUMO - Os objetivos deste trabalho foram determinar a absorção aparente, estimar as perdas endógenas fecais e a absorção real do $\mathrm{Mg}$ e determinar a ingestão ad libitum da água de beber e a concentração de Mg no soro sangüíneo de caprinos da raças Anglonubiana (AN) e Saanen (SN). Foram usados doze caprinos, seis de cada raça, com 19,8 kg PV médio. Dietas semipurificadas (baixo teor de Mg) à base de quirera de arroz, glúten de milho e celulose foram suplementadas com $\mathrm{MgO}$, para se obterem os níveis de 0,05 (sem supplementação) 0,20 e $0,35 \% \mathrm{Mg}$ (\%MS). Os níveis de Mg influenciaram os coeficientes de absorção aparente de Mg e Ca, com valores médios de 57,8; 73,9; e 73,2\% para Mg e 55,7; 39,6; e 49,5\% para Ca, para dietas com níveis 0,05; 0,20; e 0,35\% de Mg, respectivamente. Entretanto, para os coeficientes de absorção aparente de P, Na e K, não houve efeito de níveis de Mg na dieta. Os resultados de absorção real de Mg apresentaram interação de níveis de Mg e raças. A média para raça NA, no nível 0,05\% Mg, foi de 61,0\% e para os níveis 0,20 e 0,35\% Mg, 77,2 e 73,2\%, respectivamente. Entretanto, para a raça SN, as médias foram 73,3; 75,5; e 76,0\%, para os mesmos níveis, sem diferenças. A digestibilidade de matéria seca, proteína bruta e extrato não-nitrogenado diminuiu com os níveis crescentes de Mg nas dietas. As excreções fecais (7,0; 20,8; e 34,4 mg/kg PV ${ }^{0,75}$.d) e urinárias (3,9; 30,8; e 44,6 mg/kg PV ${ }^{0,75}$.d) de Mg elevaram-se com o aumento dos níveis crescentes de $\mathrm{Mg}$ nas dietas. Houve, também, influência dos níveis de $\mathrm{Mg}$ dietético sobre as concentrações de Mg do soro sangüíneo $(1,74 ; 2,23$; e 2,80 mg/dL para níveis de 0,$05 ; 0,20$; e 0,35\% de Mg, respectivamente).

Palavras-chave: absorção, Anglonubiana, caprinos, exigência, ingestão de água, magnésio, perda endógena, Saanen

\section{Endogenous Losses and Coefficients of Apparent and True Absorption of Magnesium in Goats}

\begin{abstract}
The objectives of this experiment were to determine the apparent absorption, to estimate the endogenous fecal losses and the true absorption of $\mathrm{Mg}$ and to determine the ad libitum drinking water ingestion and the $\mathrm{Mg}$ serum concentration for Anglonubian (AN) and Saanen (SN) goat breeds. Twelve kids, six of each breed, with average $19.8 \mathrm{~kg} \mathrm{LW}$, were used. Semipurified diets (low Mg content) based on cracked rice, corn gluten meal and cellulose were supplemented with $\mathrm{MgO}$ to obtain the levels of .05 (without supplementation), .20 and $.35 \%$ of $\mathrm{Mg}(\% \mathrm{DM})$. The levels of $\mathrm{Mg}$ affected the coefficient of apparent absorption of $\mathrm{Mg}$ and Ca, with average values of 57.8, 73.9, and 73.2\% for $\mathrm{Mg}$ and 55.7, 39.6 and 49.5\% for Ca for diets with .05, .20, and .35\% $\mathrm{Mg}$, respectively. However, there was no effect of the dietary $\mathrm{Mg}$ level on the coefficient of apparent absorption of P, $\mathrm{Na}$ and $\mathrm{K}$. An interaction between $\mathrm{Mg}$ level and breeds was observed for the real absorption of $\mathrm{Mg}$. The mean for $\mathrm{AN}$ breed, on the level .05\% $\mathrm{Mg}$ was $61.0 \%$ and for the levels 0.20 and $0.35 \% \mathrm{Mg}, 77.2$ and $73.2 \%$, respectively. However, for SN breed the means were 73.3, 75.5 and 76.0\%, for the same levels, without differences. The digestibility of dry matter, crude protein, and nitrogen free extract decreased with the crescent dietary $\mathrm{Mg}$ level. The fecal (7.0, $20.8 \mathrm{and} 34.4 \mathrm{mg} / \mathrm{kg}$ $\mathrm{LW}^{0.75}$.d) and urinary $\left(3.9,30.8\right.$ and $44.6 \mathrm{mg} / \mathrm{kg} \mathrm{LW}{ }^{0.75}$.d) $\mathrm{Mg}$ excretion increased with the crescent dietary Mg level. There was also influence of the dietary $\mathrm{Mg}$ level on the blood serum $\mathrm{Mg}$ concentration (1.74, 2.23 and $2.80 \mathrm{mg} / \mathrm{dL}$ for $.05, .20$, and $.35 \% \mathrm{Mg}$, respectively).
\end{abstract}

Key Words: absorption, Anglonubian, goats, requirement, water ingestion, magnesium, endogenous loss, Saanen

\section{Introdução}

O uso de fontes de magnésio para suplementação de rações baseia-se em dados estrangeiros de exigências de ovinos e bovinos, não havendo dados específicos para a espécie caprina.

O AGRICULTURAL RESEARCH COUNCIL
- ARC (1980) não traz referências de exigências de nutrientes para caprinos e as primeiras recomendações foram publicadas somente no NATIONAL RESEARCH COUNCIL - NRC (1981). Entre os minerais, o magnésio $(\mathrm{Mg})$ é um dos elementos que requer pesquisas.

Segundo o ARC (1980), as estimativas das per-

\footnotetext{
${ }^{1}$ Parte de Dissertação de Mestrado da primeira autora.Trabalho parcialmente financiado pela FUNDUNESP, SP.

${ }^{2}$ Pós-graduando da FCAVJ/UNESP, Zootecnia, Produção Animal.

${ }^{3}$ Professor do Depto de Nutrição Animal e Pastagens da FCAVJ/UNESP.

${ }^{4}$ Professor do Depto de Ciências Exatas da FCAVJ/UNESP.
} 
das fecais endógenas do magnésio podem ser obtidas por intermédio de três procedimentos: 1) extrapolação para o nível de ingestão zero da regressão da perda fecal de magnésio, em função da ingestão de magnésio de dietas naturais; 2) medidas de excreção fecal obtidas com dietas artificiais extremamente pobres em magnésio; e 3 ) método de diluição de isótopo. O comitê concluiu que as perdas endógenas fecais são 3,0 e 2,0 mg Mg/kg PV/dia, respectivamente, para ovinos e bovinos adultos e para lactantes. As perdas endógenas urinárias foram consideradas insignificantes em animais alimentados com dietas artificiais pobres em magnésio, sendo, portanto, desprezadas. A estimativa das exigências é feita em dois estádios: a) a exigência líquida é calculada a partir de estimativas de retenção e excreção do elemento, durante o crescimento, a gestação e a lactação, e das perdas inevitáveis - que são as endógenas; b) a exigência total do mineral na dieta é calculada dividindo-se a exigência líquida por um fator médio, que representa a proporção do mineral da dieta que é absorvido. Esse fator médio (coeficiente de absorção real) é estimado a partir de dados de experimentos de metabolismo (coleta de fezes e urina), em animais alimentados com dietas contendo níveis de Mg próximos ou abaixo das exigências (BOIN, 1985).

A absorção tem sido estudada, em ruminantes, por meio dos procedimentos comparativo e direto. $\mathrm{O}$ método comparativo consiste do fornecimento de dietas pobres ou deficientes em magnésio, em que o nível do elemento no sangue é positivamente correlacionado com o nível de absorção pelo trato digestivo. O procedimento direto determina a absorção aparente, por meio de estudos convencionais de digestibilidade, pela medição da quantidade de magnésio ingerido e excretado nas fezes. Os dois métodos têm sido utilizados para estudar os diferentes fatores que controlam a disponibilidade e absorção de magnésio da forragem (MINSON, 1990). Os valores do coeficiente de absorção real do magnésio apresentam resultados médios de 29,4\% para fenos, gramíneas e concentrados (ARC, 1980).

FIELD (1961), em estudos de absorção do magnésio, com ovinos, indicou que grande parte do magnésio foi absorvida no final do intestino delgado, podendo ocorrer alguma absorção adicional no intestino grosso. TOMAS e POTTER (1976) observaram que o magnésio, infundido no omaso ou abomaso de ovinos adultos, com 2 a 5 anos de idade e $40 \mathrm{~kg}$ de peso vivo, foi completamente recuperado no duodeno. Em contraste, 36 a $61 \%$ do magnésio infundido no rúmen não foram recuperados no duodeno, sugerindo que substancial absorção do magnésio ocorreu no rúmen-retículo. Consideraram, ainda, que a absorção pós-ruminal pode ser insuficiente para manter a condição normal de magnésio no organismo do animal. MARTENS e RAYSSIGUIER (1980) reportaram que o mecanismo de absorção do magnésio, estudado in vitro com mucosa isolada de rúmen de ovinos, ocorre por processo ativo ligado ao sódio e a absorção de magnésio, no retículorúmen, é reduzida pela baixa relação Na:K no meio.

ALLSOP e ROCK $(1972,1979)$ verificaram relações entre a concentração de magnésio fecal e concentração no plasma. Dietas artificiais isentas de magnésio foram suplementadas com infusão intravenosa de magnésio. Os resultados obtidos consistiram de pequeno aumento na excreção fecal de magnésio, com aumento na concentração plasmática.

O presente trabalho teve como objetivos determinar a absorção aparente do magnésio, estimar as perdas endógenas fecais e a absorção real, comparar a ingestão ad libitum de água de bebida e, ainda, observar as concentrações do magnésio no soro sangüíneo, utilizando-se ração suplementada com óxido de magnésio ( $\mathrm{MgO}$ ) e caprinos das raças Anglonubiana e Saanen.

\section{Materiais e Métodos}

O trabalho foi realizado no Setor de Avaliação dos Alimentos e Balanços Nutricionais do Departamento de Nutrição Animal e Pastagens da Faculdade de Ciências Agrárias e Veterinárias, Câmpus de Jaboticabal/UNESP, com duração de 70 dias, sendo a temperatura média de $23,6^{\circ} \mathrm{C}$ e a umidade relativa de $80,1 \%$.

\section{Materiais}

Foram utilizados 12 cabritos, machos inteiros, seis da raça Anglonubiana (AN) e seis da raça Saanen (SN), com, em média, 6 meses de idade e $19,8 \mathrm{~kg}$ de peso vivo (PV).

Durante a adaptação às rações, os animais foram alojados em baias coletivas, cujas instalações eram de alvenaria. Em uma das baias, o piso foi coberto com cama de maravalha e, na outra, havia um ripado de madeira suspenso $(20,0 \mathrm{~cm})$, favorecendo, assim, o conforto aos animais. Foram distribuídos um cocho e um bebedouro para cada par de animal.

As gaiolas de metabolismo eram de metal, próprias para ensaios com pequenos ruminantes, com 
piso de chapa metálica perfurada para vazão da urina. As gaiolas foram adaptadas com comedouros e bebedouros individuais, confeccionados de fibra sintética, com diâmetro de $25,0 \mathrm{~cm}$ e profundidade de $18,0 \mathrm{~cm}$. Os animais ficaram restritos aos movimentos de apenas deitare levantar, pois, devido ao temperamento inquieto da espécie, foram contidos com coleiras presas às gaiolas por correntes de $30 \mathrm{~cm}$ de comprimento.

As fezes foram coletadas em sacolas de tecido de napa, a urina em baldes plásticos, posicionados na parte posterior das gaiolas, e o sangue foi retirado com agulha descartável 40/12, pela punção da veia jugular.

\section{Métodos}

Os estudos de absorção aparente e real foram efetuados por intermédio do método convencional de digestibilidade, em que os animais receberam uma ração semipurificada para o magnésio, medindo-se a quantidade de magnésio ingerido e excretado nas fezes. Utilizou-se análise de regressão linear para obtenção das estimativas das perdas endógenas fecais (ARC, 1980; BOIN, 1985; e MINSON, 1990).

Os ingredientes das dietas foram selecionados, em virtude dos baixos níveis de magnésio apresentados. A dieta foi elaborada à base de quirera de arroz, farelo de glúten de milho, fosfato bicálcico, sal comum e núcleo mineral. Como volumoso, foi utilizada celulose (papelão) proveniente de eucalipto, a qual foi triturada, constituindo uma dieta semipurificada para o magnésio, e suplementada com óxido de magnésio $(\mathrm{MgO})$.

Para obter consumo de matéria seca de $2,0 \%$ do peso vivo e ganho de $50,0 \mathrm{~g}$ por dia, seguiram-se as recomendações do NRC (1981). Ajustando o consumo da dieta, foram oferecidos aos animais 200,0 g de concentrado e 200,0 g do volumoso, divididos em duas refeições por dia.

Com base em exigências de magnésio para ovinos, que variam de 0,12 a $0,18 \%$ (NRC, 1978), e para bovinos, de 0,07 a $0,30 \%$, dependendo da categoria animal (NRC, 1989), adotou-se $0,20 \%$ da matéria seca oferecida como referencial para suplementação do elemento na dieta. Para a análise de regressão linear a partir do valor $0,20 \%$ de $\mathrm{Mg}$, utilizaram-se mais dois pontos considerados equidistantes, um abaixo $(0,05 \%)$ e outro acima $(0,35 \%)$ do valor referido. A dieta balanceada continha $0,05 \% \mathrm{Mg}$ na $\mathrm{MS}$, tendo sido realizadas suplementações com $\mathrm{MgO}$ (60\% de $\mathrm{Mg}$ ). Para atingir o nível de 0,20 e 0,35\%, os animais receberam 1,0 e 1,75 g/dia, respectivamente. As suplementações foram feitas adicionando-se $\mathrm{MgO}$ ao concentrado no momento do arraçoamento.
A composição química dos ingredientes utilizados e a composição percentual e química do concentrado encontram-se na Tabela 1.

A quantidade de água oferecida permitia consumo "ad libitum". Pela manhã, antes do fornecimento do concentrado, retirava-se o resto de água do bebedouro, media-se seu volume e, então, descartava-se. Em seguida, adicionou-se novo volume conhecido de água, limpa e fresca. As medidas dos volumes de água foram realizadas em provetas de $1000 \mathrm{~mL}$.

\section{Manejo experimental e coleta de amostras}

Ao início da fase experimental, durante 10 dias, os animais foram agrupados em baias coletivas, formando os grupos relativos às raças. Os animais foram everminados por via oral. Foi feita identificação nos animais com números, por meio de marcação à tinta, entre a paleta e as costelas. Os cascos foram aparados a cada 30 dias. A adaptação teve duração de 21 dias, 10 em baias coletivas e 11 nas gaiolas de metabolismo individuais. Os alimentos foram oferecidos em dois períodos, 8 e 17 h. Oóxido de magnésio foi adicionado ao concentrado no arraçoamento das $8 \mathrm{~h}$ e, após esse consumo, foi oferecida celulose.

$\mathrm{O}$ período de coleta de amostras foi sete dias. $\mathrm{O}$ concentrado e a celulose foram amostrados diariamente. Foram feitas coletas totais de fezes e urina pela manhã e, então, retiradas alíquotas de 40 e $10 \%$, respectivamente. Das sobras diárias foram retiradas amostras correspondentes a $30 \%$ do total.

As amostras de fezes, compostas por animal, foram acondicionadas em sacos plásticos e, imediatamente após a coleta, congeladas. As amostras de urina foram acondicionadas em recipiente de vidro, resfriadas durante o período de coleta e, posteriormente, congeladas em freezer. A acidificação da urina foi feita colocando-se diariamente $10 \mathrm{~mL}$ de solução de ácido clorídrico, 6,03 moles/L (diluição na proporção de 1:1) nos baldes de coleta, o que manteve o pH próximo de 2 .

Coletaram-se $5 \mathrm{~mL}$ de sangue e extraiu-se o soro por centrifugação, que, posteriormente, foi congelado. Este processo foi realizado no último dia de cada período de coleta, 3 horas após o fornecimento da ração (ALLSOP e ROOK, 1979; GREENE et al., 1983a, b).

\section{Preparo das amostras e análises químicas}

As amostras de fezes foram descongeladas e, posteriormente, submetidas à pré-secagem, em estufa com circulação forçada de ar, durante 48 horas, à temperatura de 60 a $65^{\circ} \mathrm{C}$, e então moídas. As amostras de alimentos e fezes foram moídas em 
Tabela 1 - Composição química dos ingredientes e do concentrado (\% MS)

Table 1 - Chemical composition of ingredients and concentrate (\%DM)

\begin{tabular}{|c|c|c|c|c|c|c|}
\hline \multirow[t]{2}{*}{$\begin{array}{l}\text { Composição } \\
\text { Composition }\end{array}$} & \multicolumn{5}{|c|}{$\begin{array}{l}\text { Ingrediente } \\
\text { Ingredient }\end{array}$} & \multirow[b]{2}{*}{$\begin{array}{c}\text { Composição do } \\
\text { concentrado } \\
\text { Concentrate } \\
\text { composition }\end{array}$} \\
\hline & $\begin{array}{c}\text { Celulose }^{1} \\
\text { Cellulose }\end{array}$ & $\begin{array}{l}\text { Glúten } \\
\text { Gluten }\end{array}$ & $\begin{array}{l}\text { Arroz } \\
\text { Rice }\end{array}$ & $\begin{array}{l}\text { Fosfato } \\
\text { bicálcico } \\
\text { Dicalcium } \\
\text { phosphate }\end{array}$ & $\begin{array}{c}\text { Sal e núcleo } \\
\text { mineral }^{*} \\
\text { Salt and mineral } \\
\text { premix }\end{array}$ & \\
\hline Matéria seca (\%) & 92,4 & 90,1 & 86,0 & - & & 87,30 \\
\hline Dry matter & & & & & & \\
\hline $\begin{array}{l}\text { Proteína bruta }(\%) \\
\text { Crude protein }\end{array}$ & 0,5 & 62,9 & 8,6 & - & & 25,60 \\
\hline $\begin{array}{l}\text { Energia bruta (Mcal/kg ) } \\
\text { Gross energy }\end{array}$ & 3,8 & 5,4 & 3,7 & - & & 4,00 \\
\hline $\begin{array}{l}\text { Extrato etéreo (\%) } \\
\text { Ether extract }\end{array}$ & 0,8 & 8,4 & 1,3 & & & 3,41 \\
\hline $\begin{array}{l}\text { Fibra bruta }(\%) \\
\text { Crude fiber }\end{array}$ & 77,7 & 2,9 & 1,4 & - & & 6,80 \\
\hline $\begin{array}{l}\text { Fibra em detergente neutro }(\%) \\
\text { Neutral detergent fiber }\end{array}$ & 84,2 & - & - & - & & - \\
\hline $\begin{array}{l}\text { Fibra em detergente ácido (\%) } \\
\text { Acid detergent fiber }\end{array}$ & 81,4 & - & - & - & & - \\
\hline $\begin{array}{l}\text { Lignina }(\%) \\
\text { Lignin }\end{array}$ & 4,4 & - & - & - & & - \\
\hline $\begin{array}{l}\text { Celulose }(\%) \\
\text { Cellulose }\end{array}$ & 77,4 & - & - & - & & - \\
\hline $\begin{array}{l}\text { Cinzas }(\%) \\
\text { Ash }\end{array}$ & 0,7 & 1,8 & 0,6 & - & & 4,03 \\
\hline $\mathrm{Ca}(\%)$ & 0,18 & 0,09 & 0,10 & 25,40 & & 0,60 \\
\hline $\mathrm{P}(\%)$ & 0,03 & 0,44 & 0,04 & 17,15 & & 0,81 \\
\hline $\operatorname{Mg}(\%)$ & 0,03 & 0,03 & 0,04 & - & & 0,06 \\
\hline $\mathrm{Na}(\%)$ & 0,09 & 0,01 & 0,01 & - & & 0,18 \\
\hline $\mathrm{K}(\%)$ & 0,03 & 0,06 & 0,08 & - & & 0,09 \\
\hline $\begin{array}{l}\% \text { na ração } \\
\% \text { in the diet }\end{array}$ & 50,0 & 18,3 & 30,2 & 1,2 & 0,3 & \\
\hline
\end{tabular}

1 Volumoso da ração experimental.

1 Forage of experimental diet.

* $\mathrm{ZnO} 14,2 \% ; \mathrm{FeSO}_{4} 41,5 \% ; \mathrm{Na}_{2} \mathrm{SeO}_{3}$ 0,06 \%; $\mathrm{MnSO}_{4} \cdot \mathrm{H}_{2} \mathrm{O} 33,5 \%, \mathrm{CuSO}_{4} \cdot 5 \mathrm{H}_{2} \mathrm{O} 10,4 \% ; \mathrm{CoSO}_{4} \cdot 7 \mathrm{H}_{2} \mathrm{O} 0,28 \%$.

peneira com crivo de 2,0 $\mathrm{mm}$, enquanto as sobras, em macromoinho de martelo em peneira com crivo de 1,0 mm, sendo, em seguida, armazenadas em vidros com tampa plástica.

Para determinação dos minerais nos alimentos, na ração, nas sobras e fezes, prepararam-se os extratos com solução nitro-perclórica, armazenando-os em frascos plásticos na geladeira, para posteriores leituras de $\mathrm{Mg}, \mathrm{Ca}, \mathrm{Na}$ e $\mathrm{K}$, por meio do método de espectrofotometria de absorção atômica, e P, pelo método colorimétrico (BATAGLIA et al., 1983). Para determinação de $P$, utilizou-se a solução molibdo-vanadato, efetuando-se as leituras em Espectrofotômetro Nic-88 (Bausch e Lomb).

As amostras de urina, após descongelamento, foram filtradas em papel de filtro qualitativo, para retirar as impurezas. A urina foi diluída diretamente com água deionizada somente no momento da leitura, de acordo com a metodologia de WILLIS (1961).
Após a extração do soro nos períodos de coleta, foram feitas análises com Kit-Magnésio, (Labtest), fazendo-se as leituras em Espectrofotômetro Coleman295.M, método simples e rápido que permitiu, em poucos minutos, a análise quantitativa do magnésio nas amostras desse material.

Das amostras de alimentos, sobras e fezes, foram determinados também os teores de matéria seca (MS), proteína bruta (PB), extrato etéreo (EE), fibra bruta (FB) e cinzas $(\mathrm{Cz})$, segundo recomendações de SILVA (1981), e por diferença estimou-se o extrativo não-nitrogenado (ENN). A determinação da energia bruta (EB) foi realizada por intermédio de bomba calorimétrica (Ika-Werk).

\section{Delineamento estatístico}

$\mathrm{O}$ delineamento experimental utilizado foi em blocos ao acaso, em esquema fatorial $2 \times 3$ (raças e níveis de $\mathrm{Mg}$ na ração), com dois blocos (repetição no tempo) e duas repetições dentro de cada bloco. Cada 
Rev. bras. zootec.

animal foi considerado como unidade experimental. Para verificar a significância das diferenças entre as médias dos tratamentos, foi utilizado o teste Tukey. Foram feitas análises de regressão, em função dos níveis de magnésio, para estimar as perdas endógenas fecais. As análises estatísticas foram efetuadas por intermédio do procedimento GLM do SAS (1988).

\section{Cálculos e estimativas}

O termo absorção foi empregado para os elementos minerais ( $\mathrm{Mg}, \mathrm{Ca}, \mathrm{P}, \mathrm{Na}$ e $\mathrm{K}$ ) e digestibilidade, para MS, PB, EE, FB, EB, Cz e ENN, utilizando a fórmula convencional para os cálculos: $\mathrm{CAap}=[($ Inger. total - Excret. total)/Inger. total] x 100, em que Inger. total $=$ ingerido total e Excret. total $=$ excretado total .

Para o elemento magnésio, calcularam-se os coeficientes de absorção real, subtraindo-se as perdas endógenas fecais obtidas por equações de regressão, em que X é mg Mg ingerido/kg $\mathrm{PV}^{0,75} / \mathrm{dia}$ e $\mathrm{Y}, \mathrm{mg} \mathrm{Mg}$ excretado/kg PV ${ }^{0,75} /$ dia, extrapolando para o nível zero de ingestão de magnésio, sendo CAreal $=\{[\mathrm{Mg}$ ing. $-(\mathrm{Mg}$ exc. - per.endóg. de $\mathrm{Mg})] /$ $\mathrm{Mg}$ ing. $\}$ x 100, em que $\mathrm{Mg}$ ing. é $\mathrm{Mg}$ ingerido total, $\mathrm{Mg}$ exc., $\mathrm{Mg}$ excretado fecal; e per. endóg. $\mathrm{Mg}$, perdas endógenas fecais de $\mathrm{Mg}$.

As excreções fecais e urinárias dos elementos minerais foram obtidas por meio de concentrações nas excreções diárias por unidade de tamanho metabólico $\left(\mathrm{UTM}=\mathrm{kg} \mathrm{PV}{ }^{0,75}\right)$.

\section{Resultados e Discussão}

Os resultados dos efeitos dos diferentes níveis de magnésio e de raças, sobre os coeficientes médios de absorção aparente dos elementos minerais, constam da Tabela 2.

Houve efeito significativo dos níveis de magnésio sobre os coeficientes de absorção aparente deste elemento, com médias superiores para os níveis 0,20 e $0,35 \% \mathrm{Mg}(73,9$ e 73,2\%, respectivamente), quando comparados com a média do nível $0,05 \% \mathrm{Mg}$ $(57,8 \%)$. Os percentuais encontrados sugerem influência do efeito da excreção endógena sobre a absorção aparente de nutrientes. ALLSOP e ROOK (1979) demonstraram que as perdas endógenas fecais de $\mathrm{Mg}$ em ovinos foram positivamente correlacionadas com o aumento da ingestão de $\mathrm{Mg}$, como também as concentrações no plasma. Outro fator seria a possível baixa disponibilidade do elemento nos alimentos. AMMERMAN e CHICCO (1968), em estudos de disponibilidade de sais inorgânicos de $\mathrm{Mg}$ para ovinos adultos, encontraram resultados de absorção aparente, para $\mathrm{MgO}$, de 52,0\%. PEELER (1972), ARC (1980), CONRAD et al. (1985) estabeleceram que a disponibilidade de magnésio em forragens varia de 10 a $25 \%$ e de grãos e concentrados, de 30 a $40 \%$.

Além da disponibilidade, a quantidade fornecida de magnésio na dieta que não foi suplementada

Tabela 2 - Valor de F e média dos coeficientes de absorção aparente dos elementos minerais (\%)

Table 2 - Value of $F$ and mean of the coefficients of apparent absorption of the mineral elements (\%)

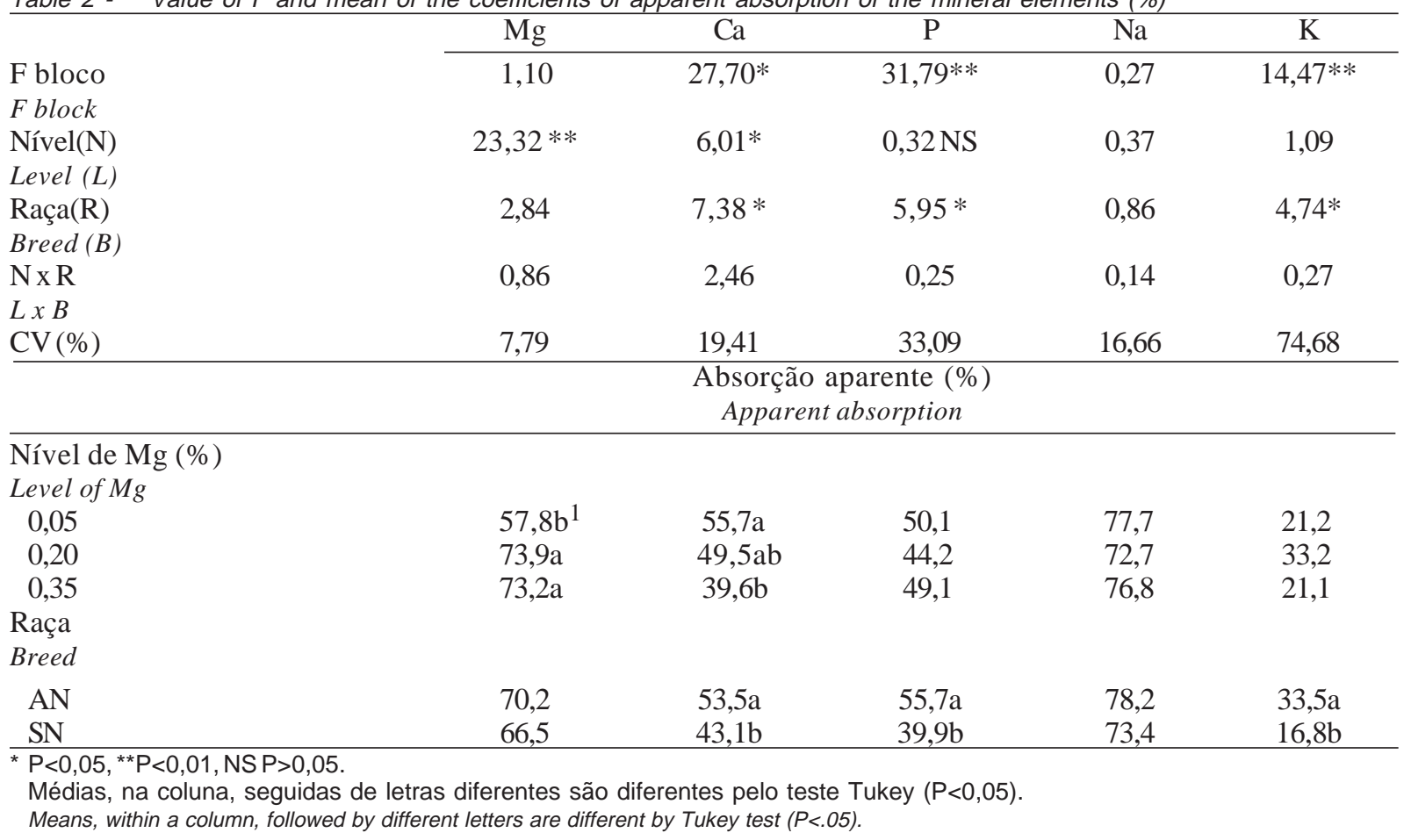


correspondeu a $50 \%$ dos requerimentos mínimos de ovinos e bovinos, $0,10 \% \mathrm{Mg}$ na $\mathrm{MS}$ ingerida (AMMERMAN e GOODRICH, 1983; NRC, 1989). $\mathrm{O}$ sódio presente no sal atendeu às exigências de ovinos e pode ter favorecido a absorção de $\mathrm{Mg}$ (TOMAS e POTTER, 1976; MARTENS e RAYSSIGUIER, 1980; GREENE et al., 1983a; e WYLIE et al. 1985). Os resultados de análises de laboratório das dietas apresentaram teores de K abaixo do esperado, oque pode ter contribuído para melhor relação de $\mathrm{Na} \mathrm{K}$, favorecendo a absorção aparente do Mg. Os níveis de Mg influenciaram os coeficientes de absorção aparente do $\mathrm{Ca}$, em que as médias foram 55,$7 ; 49,5$; e $39,6 \%$, respectivamente, para os níveis 0,$05 ; 0,20 ;$ e 0,35\% Mg. Embora no nível 0,20\% de $\mathrm{Mg}$ o resultado não tenha diferido dos demais, a absorção de Ca comportou-se de forma decrescente, de acordo com o acréscimo do nível de suplementação de $\mathrm{Mg}$ na ração. DAVENPORT (1978), MARTENS e RAYSSIGUIER (1980) e GEORGIEVSKII (1982) relataram que houve diminuição na absorção aparente de $\mathrm{Ca}$, devido à semelhança no mecanismo de absorção de $\mathrm{Ca}$ e $\mathrm{Mg}$, que ocorre por intermédio de transporte ativo. CHICCO et al. (1973) observaram que, com o aumento do Mg dietético, houve diminuição na utilização de Ca. CHESTER-JONES et al. (1990) relataram que a absorção aparente de $\mathrm{Ca}$ e $\mathrm{P}$ decresceu à medida que o nível dietético de $\mathrm{Mg}$ aumentou. Para os elementos $\mathrm{P}$, $\mathrm{Na}$ e $\mathrm{K}$, não houve efeito dos níveis de $\mathrm{Mg}$ sobre a absorção aparente. Esses dados contrastam com os de CHESTER-JONES et al. (1990), os quais constataram que a absorção aparente de P diminuiu linearmente com o aumento da ingestão de Mg. Entretanto, os níveis de Mg empregados por esses autores foram, 0,$3 ; 1,2 ; 2,4 ; \mathrm{e} 4,8 \%$ na MS, bem mais elevados que os utilizados neste trabalho. Para a absorção aparente de $\mathrm{K}$, o nível de $0,20 \% \mathrm{Mg}$ apresentou resultado superior aos demais. Também GREENE et al. (1983a, b), ao utilizarem o nível de $0,20 \% \mathrm{Mg}$ na MS da ração, verificaram melhora na absorção de $\mathrm{K}$ em relação ao nível $0,10 \% \mathrm{Mg}$.

Houve efeito das raças sobre os coeficientes de absorção aparente do $\mathrm{Ca}, \mathrm{P}$ e $\mathrm{K}$, sendo que a raça Anglonubiana apresentou médias superiores (53,5; 55,7; e 33,5, respectivamente), quando comparadas às médias da raça Saanen $(43,1 ; 39,9$; e 16,8\%, na mesma ordem). Não houve efeito de raças sobre as absorções aparentes de $\mathrm{Mg}$ e $\mathrm{Na}$.

Os coeficientes de absorção real do magnésio foram estimados com base nas perdas endógenas fecais, para cada raça, utilizando análise de regressão, em que $\mathrm{Y}$ é $\mathrm{mg}$ de $\mathrm{Mg}$ excretado/kg PV ${ }^{0,75 / d i a ~ e ~} \mathrm{X}, \mathrm{mg}$ de $\mathrm{Mg}$

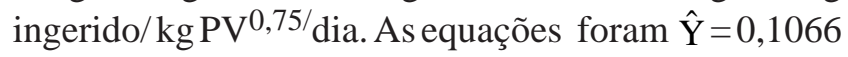
$+0,2666 \mathrm{X}, \mathrm{r}^{2}=0,82(\mathrm{P}<0,01)$ para a raça $\mathrm{AN}$ e $\hat{\mathrm{Y}}=3,5746+0,2409 \mathrm{X}, \mathrm{r}^{2}=0,95(\mathrm{P}<0,01)$ para a raça $\mathrm{SN}$. Assim, foram usados, como perdas endógenas fecais, valores de 0,1066 e 3,5746 mg Mg/kg $\mathrm{PV}^{0,75 / d i a}$, respectivamente, para as raças AN e SN.

Houve interação entre níveis e raças para os coeficientes de absorção real do $\mathrm{Mg}$ (Tabela 3). Dentro da raça $\mathrm{AN}$, o uso do nível $0,05 \% \mathrm{Mg}$ foi o que apresentou a menor média de absorção real do $\mathrm{Mg}$ (61,0\%), se comparada às dos níveis $0,20 \mathrm{e}$ $0,35 \% \mathrm{Mg}(77,2$ e $73,2 \%$, respectivamente). Isto pode ser atribuído ao fato de que esta raça apresentou, como perdas endógenas fecais, valor inferior (0,1066 mg Mg/UTM/dia) ao valor médio de 3,0 mg de $\mathrm{Mg} / \mathrm{kg}$ PV estabelecido pelo ARC (1980), o que equivaleria a $6,33 \mathrm{mg}$ de $\mathrm{Mg} / \mathrm{kg} \mathrm{PV} 0,75 /$ dia para estes animais. Com a suplementação de $\mathrm{Mg}$, pode-se observar que os coeficientes de absorção real foram maiores. AMMERMAN et al. (1972) obtiveram valores médios de $72,9 \%$ para absorção real de $\mathrm{Mg}$, utilizando-se carneiros castrados, com peso vivo médio de $28,6 \mathrm{~kg}$, recebendo dietas suplementadas com diversas fontes de $\mathrm{Mg}$.

$\mathrm{Na}$ Tabela 4 encontram-se os resultados dos efeitos dos níveis de $\mathrm{Mg}$ e das raças, sobre os coeficientes de digestibilidade aparente de MS, PB, $\mathrm{EE}, \mathrm{FB}, \mathrm{EB}, \mathrm{Cz}$ e ENN. Os níveis de Mg influíram na digestibilidade aparente de MS, PB, Cz e ENN. Os animais que receberam a dieta sem suplementação (nível $0,05 \% \mathrm{Mg}$ ) apresentaram médias de digestibilidade aparente de 88,4;80,6; 59,2; e 90,2, respectivamente, e os que receberam a dieta com $0,35 \% \mathrm{Mg}, 85,2 ; 69,1 ; 42,1$; e 86,8 , na mesma se-

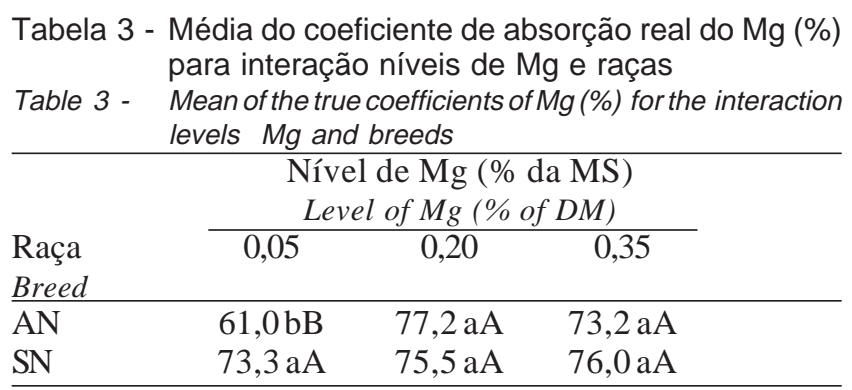

Médias, na linha/coluna, seguidas de letras diferentes minúsculas/ maiúsculas são diferentes $(\mathrm{P}<0,05)$ pelo teste Tukey.

Means, within a row/column, followed by different letters small/capital are different $(P<.05)$ by Tukey test. 
Rev. bras. zootec.

qüência. A dieta com $0,20 \% \mathrm{Mg}$ apresentou resultados que não diferiram dos outros níveis. A diminuição na digestibilidade da MS, devido aos níveis crescentes de $\mathrm{Mg}$ na dieta, pode ser atribuída ao fato de que íons $\mathrm{Mg}^{++}$são responsáveis, em parte, pela retenção de água na luz intestinal, para manter o equilíbrio osmótico, provocando a formação de fezes amolecidas e taxa de passagem mais alta (DAVENPOT, 1978). Em consequência, os resultados para $\mathrm{PB}$ e ENN, por perfazerem grande parte da MS nas dietas experimentais, sofreram as mesmas influências. Estes resultados estão de acordo com os de REID et al. (1984) e CHESTER-JONES et al. (1990), que obtiveram diminuições na digestibilidade aparente da MS com o aumento de $\mathrm{Mg}$ na dieta.

De forma semelhante, a queda na digestibilidade aparente da cinza pode ser explicada pelo fato de que $\mathrm{Ca}$ e $\mathrm{P}$ perfazem a maior parte desta fração e, devido à suplementação com níveis crescentes de $\mathrm{Mg}$, o Ca, principalmente, pode ter sua absorção reduzida (Tabela 2). SCHNEIDER e FLATT (1975) mencionaram que certas porções da cinza, particularmente ferro, cálcio, magnésio e fósforo, são em grande parte ou totalmente excretadas do corpo por meio das fezes.

As raças apresentaram diferença na digestibilidade apenas para $\mathrm{Cz}$, sendo a média da raça $\mathrm{AN}$ superior $(55,9 \%)$ à da raça $\mathrm{SN}(43,8 \%)$.

As influências dos níveis de $\mathrm{Mg}$ e das raças sobre a excreção fecal dos elementos minerais em estudo estão apresentadas na Tabela 5. Houve efeito significativo dos níveis de $\mathrm{Mg}$ na dieta somente para excreção fecal de $\mathrm{Mg}$, resultando em valores de 7,0; 20,8; e 34,4 mg Mg/kg PV $0,75 /$ dia, para os níveis 0,05 ; 0,20 ; e $0,35 \% \mathrm{Mg}$, respectivamente. GREENE et al. (1983a), quando utilizaram ovinos recebendo dietas com $0,20 \% \mathrm{Mg}$, encontraram maior excreção de $\mathrm{Mg}$ nas fezes que os animais alimentados com dietas contendo 0,10\%. GREENE et al. (1983b) mostraram que a excreção fecal de $\mathrm{Mg}$ aumentou de 0,77 para $1,08 \mathrm{~g} /$ dia, quando a dieta foi suplementada com $\mathrm{Mg}$, representando $43 \%$ de aumento.

Houve influência das raças sobre a excreção fecal de $\mathrm{K}$, em que a média foi de 14,6 e 19,5 mg K/ $/ \mathrm{kg}$ $\mathrm{PV}^{0,75} /$ dia, respectivamente, para $\mathrm{AN}$ e $\mathrm{SN}$, podendo-se constatar que ocorreu relação entre a maior absorção de K (33,5 e 16,8\% para $\mathrm{AN}$ e SN) e a menor

Tabela 4 - Valor de F e médias para os coeficientes de digestibilidade aparente da matéria seca e nutrientes (\%)

Table 4 - Value of $F$ and means of the coefficients of apparent digestibility of dry matter and nutrients (\%)

\begin{tabular}{|c|c|c|c|c|c|c|c|}
\hline \multirow[t]{2}{*}{$\begin{array}{l}\text { Fonte de variação } \\
\text { Source of variation }\end{array}$} & \multicolumn{7}{|c|}{$\begin{array}{c}\text { Nutriente } \\
\text { Nutrient }\end{array}$} \\
\hline & $\begin{array}{l}\text { MS } \\
D M\end{array}$ & $\begin{array}{l}\mathrm{PB} \\
C P\end{array}$ & $\mathrm{EE}$ & $\begin{array}{l}\mathrm{FB} \\
C F\end{array}$ & $\begin{array}{l}\mathrm{EB} \\
G E\end{array}$ & $\begin{array}{c}\mathrm{CZ} \\
M M\end{array}$ & $\begin{array}{l}\mathrm{ENN} \\
N F E\end{array}$ \\
\hline $\begin{array}{l}\text { F bloco } \\
\text { F block }\end{array}$ & 0,13 & 0,50 & 0,02 & 2,27 & 0,20 & $5,68 *$ & $5,86 *$ \\
\hline $\begin{array}{l}\text { Nível }(\mathrm{N}) \\
\text { Level }(L)\end{array}$ & $3,90 *$ & $5,16 *$ & 0,45 & 0,44 & $3,27 \mathrm{~N}$ & $6,62 * *$ & $4,93 *$ \\
\hline $\begin{array}{l}\text { Raça (R) } \\
\text { Breed }(B)\end{array}$ & 0,18 & 1,03 & 0,03 & 1,37 & 0,04 & $9,59 * *$ & 0,06 \\
\hline $\begin{array}{l}\mathrm{N} \times \mathrm{R} \\
L \times B\end{array}$ & 0,90 & 0,74 & 1,07 & 0,88 & 1,16 & 0,36 & 0,38 \\
\hline $\mathrm{CV}(\%)$ & 2,6 & 9,6 & 10,0 & 3,4 & 2,7 & 19,1 & 2,6 \\
\hline Nível de Mg (\%) & \multicolumn{7}{|c|}{ Digestibilidade aparente (\%) } \\
\hline Level of $M g$ & \multicolumn{7}{|c|}{ Apparent digestibility } \\
\hline $\begin{array}{l}0,05 \\
0,20 \\
0,35\end{array}$ & $\begin{array}{l}88,4 \mathrm{a}^{1} \\
86,9 \mathrm{ab} \\
85,2 \mathrm{~b}\end{array}$ & $\begin{array}{l}80,6 \mathrm{a} \\
73,9 \mathrm{ab} \\
69,1 \mathrm{~b}\end{array}$ & $\begin{array}{l}73,1 \\
71,2 \\
69,8\end{array}$ & $\begin{array}{l}92,9 \\
93,7 \\
92,2\end{array}$ & $\begin{array}{l}87,3 \\
85,8 \\
84,3\end{array}$ & $\begin{array}{l}59,2 \mathrm{a} \\
48,2 \mathrm{ab} \\
42,1 \mathrm{~b}\end{array}$ & $\begin{array}{l}90,2 \mathrm{a} \\
87,6 \mathrm{ab} \\
86,8 \mathrm{~b}\end{array}$ \\
\hline $\begin{array}{l}\text { Raça } \\
\text { Breed }\end{array}$ & & & & & & & \\
\hline $\begin{array}{l}\mathrm{AN} \\
\mathrm{SN}\end{array}$ & $\begin{array}{l}87,0 \\
86,7 \\
\end{array}$ & $\begin{array}{l}76,0 \\
73,1 \\
\end{array}$ & $\begin{array}{l}71,6 \\
71,1 \\
\end{array}$ & $\begin{array}{l}92,2 \\
93,7\end{array}$ & $\begin{array}{l}85,9 \\
85,7 \\
\end{array}$ & $\begin{array}{l}55,9 \mathrm{a} \\
43,8 \mathrm{~b}\end{array}$ & $\begin{array}{l}88,3 \\
88,1\end{array}$ \\
\hline
\end{tabular}


ALCALDE et al.

excreção fecal. Houve, ainda, interação entre os níveis de $\mathrm{Mg}$ na dieta e nas raças, sobre a excreção fecal de Ca. Pela análise da Tabela 6, constata-se que houve efeito entre o nível 0,35\% $\mathrm{Mg}$ e as raças; para AN e SN, a média de excreção fecal foi, respectivamente, $70,84 \mathrm{mg}$ e $119,20 \mathrm{Ca} / \mathrm{kg} \mathrm{PV}^{0,75} /$ dia. Entre os níveis de $\mathrm{Mg}$ estudados, também houve diferença dentro da raça $\mathrm{SN}$, na qual, para os níveis 0,05 e $0,20 \% \mathrm{Mg}$, os valores foram 62,4 e $82,0 \mathrm{mg} \mathrm{Ca} / \mathrm{kg} \mathrm{PV}^{0,75} / \mathrm{dia}$, respectivamente, diferindo do nível $0,35 \%$, em que o valor foi de $119,20 \mathrm{mg} \mathrm{Ca} / \mathrm{kg} \mathrm{PV}^{0,75} / \mathrm{dia}$.

Os níveis de $\mathrm{Mg}$ nas dietas resultaram em diferenças nas excreções urinárias de $\mathrm{Mg}$ e $\mathrm{Ca}$ (Tabela 7). À medida que aumentaram os níveis de $\mathrm{Mg}$, aumentou a excreção urinária de $\mathrm{Mg}(3,9 ; 30,8$; e 44,6 mg/PV $0,75 /$ dia, respectivamente, nos níveis 0,05; 0,20; e 0,35\%). CHICCO et al. (1973) mostraram que, com o aumento do magnésio na dieta de 750 para 7750 ppm, a excreção urinária aumentou de $0,124 \mathrm{~g}$ para 1,324 g/dia. GREENE et al. (1983a) observaram que a excreção urinária de $\mathrm{Mg}$ aumentou com os níveis de $\mathrm{Mg}$ na dieta, 0,10 e $0,20 \%$, constatando que o aumento ocorreu, provavelmente, em virtude do incremento da absorção. O efeito dos níveis de $\mathrm{Mg}$ sobre a diminuição da excreção de $\mathrm{Ca}$ na urina pode estar relacionado à diminuição na absorção aparente de $\mathrm{Ca}$, devido ao aumento dos níveis de $\mathrm{Mg}$ na ração.

Os níveis de $\mathrm{Mg}$ e as raças não influenciaram a excreção urinária dos elementos $\mathrm{P}, \mathrm{Na}$ e K (Tabela 7). As estimativas das perdas endógenas urinárias, para cada raça, foram efetuadas por meio de análises de regressão, em que $\mathrm{Y}$ é $\mathrm{mg}$ de $\mathrm{Mg}$ excretado na urina/kg $\mathrm{PV}^{0,75 / \text { dia }}$ e $\mathrm{X}, \mathrm{mg}$ de $\mathrm{Mg}$ ingerido/kg $\mathrm{PV}^{0,75 / \text { dia }}$. As equações foram $\hat{\mathrm{Y}}=-1,8757+0,3374 \mathrm{X}$, $\mathrm{r}^{2}=0,73(\mathrm{P}<0,01)$ para raça $\mathrm{AN}$ e $\hat{\mathrm{Y}}=-3,0320+$ $0,4343 \mathrm{X}, \mathrm{r}^{2}=0,85(\mathrm{P}<0,01)$ para raça $\mathrm{SN}$. O ARC (1980) relatou que as perdas endógenas urinárias são consideradas insignificantes em animais alimentados com dietas artificiais baixas em magnésio, podendo ser desconsideradas.

Na Tabela 8 estão presentes os efeitos dos níveis

Tabela 5 - Valor de F e médias para excreção fecal (mg/PV0,75/dia) dos elementos minerais

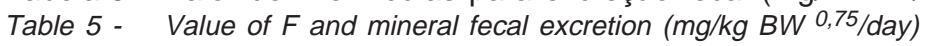

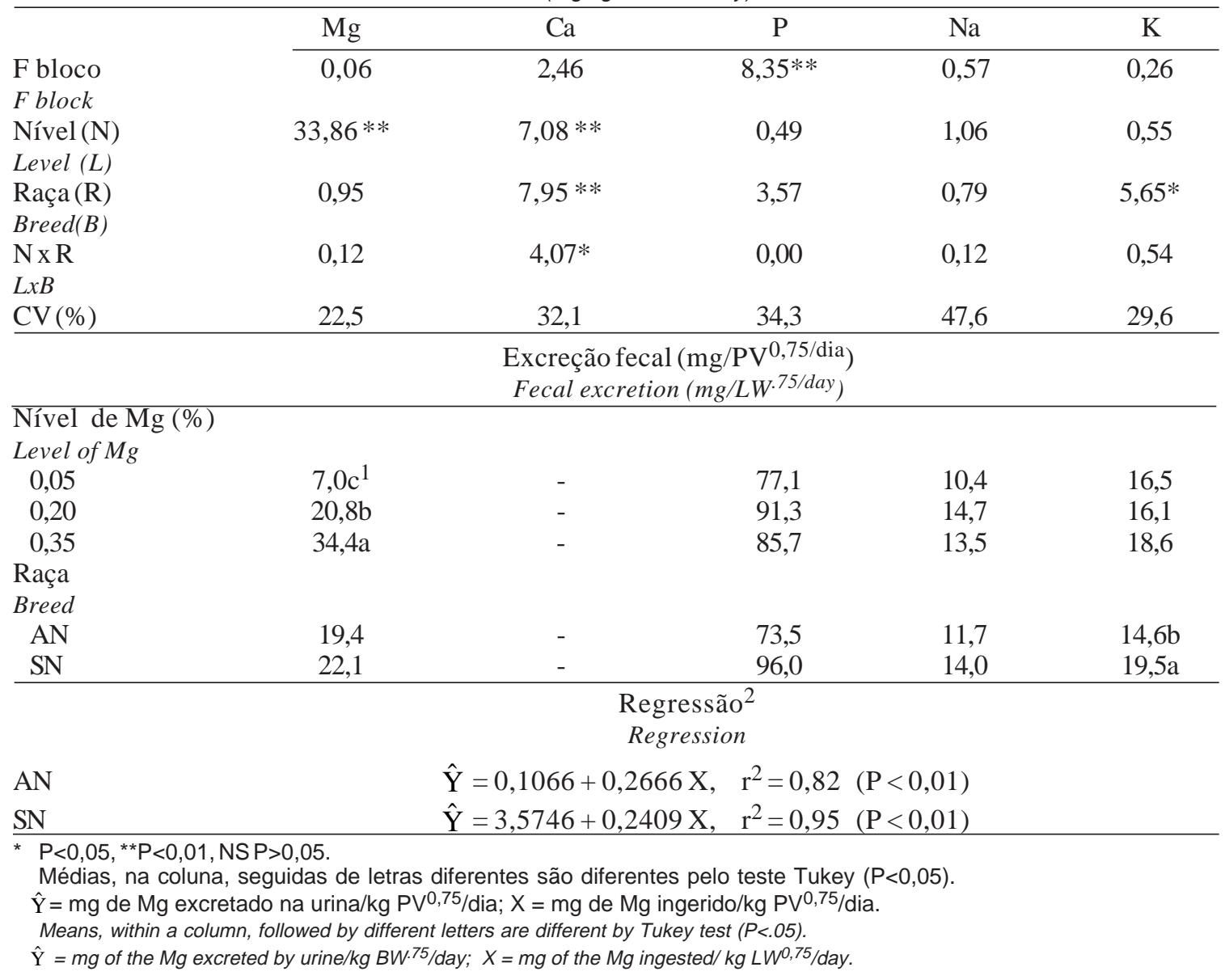


Rev. bras. zootec.

Tabela 6 - Valor da interação níveis de Mg x raças para a excreção fecal de $\mathrm{Ca}$ (mg/kg PV0,75/dia)

Table 6 - Value from levels of magnesium $x$ Ireeds for fecal excretions of $\mathrm{Ca}(\mathrm{mg} / \mathrm{kg} \mathrm{LW} 0.75 /$ day)

Nível de Mg

Level of $M g$

\begin{tabular}{lccc} 
Raça & 0,05 & 0,20 & 0,35 \\
\cline { 2 - 4 } Breed & & & \\
\hline AN & 61,8 a A & 70,4 a A & 70,8 a B \\
SN & 62,4 b A & 82,0 a A & 119,2 a A
\end{tabular}

SN $\quad 62,4 \mathrm{~b} A \quad 82,0 \mathrm{~b} A \quad 119,2 \mathrm{a} A$

Médias, na coluna, seguidas de letras diferentes são diferentes pelo teste Tukey $(\mathrm{P}<0,05)$.

Means, within a column, followed by different letters are different by Tukey test $(P<.05)$. de $\mathrm{Mg}$ e das raças nas concentrações dos elementos minerais no soro sangüíneo. Pode-se observar que tanto os níveis de $\mathrm{Mg}$ quanto as raças não produziram diferenças sobre a concentração sorológica dos minerais $\mathrm{Ca}$, $\mathrm{Na}$ e K. Para a concentração de $\mathrm{Mg}$, houve efeito dos níveis de $\mathrm{Mg}$ nas dietas. CHICCO et al. (1973) e CHESTER-JONES et al. (1990) verificaram que o teor de Mg no plasma aumentou, quando o $\mathrm{Mg}$ dietético se elevou. Neste trabalho, os resultados médios de $\mathrm{Mg}$ obtidos no soro,

Tabela 7 - Valor de $\mathrm{F}$ e média para excreção dos elementos minerais

Table 7 - Value of $F$ and urinary excretion of the mineral elements

Fonte de variação $\quad$ Mineral

\begin{tabular}{|c|c|c|c|c|c|}
\hline Source of variation & $\mathrm{Mg}$ & $\mathrm{Ca}$ & $\mathrm{P}$ & $\mathrm{Na}$ & $\mathrm{K}$ \\
\hline $\begin{array}{l}\text { F bloco } \\
\text { F block }\end{array}$ & 0,45 & 0,14 & 0,70 & $6,64 * *$ & 3,98 \\
\hline $\begin{array}{l}\text { Nível }(\mathrm{N}) \\
\text { Level }(L)\end{array}$ & $20,36 * *$ & $6,30 * *$ & 0,03 & 0,53 & 1,18 \\
\hline $\begin{array}{l}\text { Raça }(\mathrm{R}) \\
\text { Breed }(B)\end{array}$ & 2,13 & 0,22 & 3,15 & 0,79 & 0,24 \\
\hline $\begin{array}{l}\mathrm{N} \times \mathrm{R} \\
L \times B \\
\end{array}$ & 0,74 & 0,76 & 0,40 & 0,43 & 0,20 \\
\hline $\mathrm{CV}(\%)$ & 49,16 & 60,01 & 142,30 & 39,63 & 47,80 \\
\hline $\begin{array}{l}\text { Nível de } \mathrm{Mg}(\%) \\
\text { Level of } \mathrm{Mg}\end{array}$ & \multicolumn{5}{|c|}{ Excreção urinária $\left(\mathrm{mg} / \mathrm{PV}(L W)^{0,75} . \mathrm{d}\right)$} \\
\hline $\begin{array}{l}0,05 \\
0,20 \\
0,35\end{array}$ & $\begin{array}{l}3,9 \mathrm{~b}^{1} \\
30,8 \mathrm{a} \\
44,6 \mathrm{a}\end{array}$ & $\begin{array}{c}13,6 \mathrm{a} \\
6,8 \mathrm{~b} \\
5,1 \mathrm{~b}\end{array}$ & $\begin{array}{l}0,03 \\
0,02 \\
0,03\end{array}$ & $\begin{array}{l}45,2 \\
55,5 \\
50,6\end{array}$ & $\begin{array}{l}9,7 \\
7,0 \\
7,3\end{array}$ \\
\hline $\begin{array}{l}\text { Raça } \\
\text { Breed }\end{array}$ & & & & & \\
\hline $\begin{array}{l}\text { AN } \\
\text { SN }\end{array}$ & $\begin{array}{l}22,6 \\
30,3\end{array}$ & $\begin{array}{l}8,0 \\
9,0\end{array}$ & $\begin{array}{l}0,04 \\
0,01\end{array}$ & $\begin{array}{l}46,8 \\
54,1\end{array}$ & $\begin{array}{l}8,4 \\
7,6\end{array}$ \\
\hline
\end{tabular}

\section{Regressão ${ }^{2}$}

Regression

\begin{tabular}{|c|c|}
\hline AN & $\hat{\mathrm{Y}}=-1,8757+0,3374 \mathrm{X}, \quad \mathrm{r}^{2}=0,73 \quad(\mathrm{P}<0,01)$ \\
\hline SN & $\hat{\mathrm{Y}}=-3,0320+0,4343 \mathrm{X}, \quad \mathrm{r}^{2}=0,85 \quad(\mathrm{P}<0,01)$ \\
\hline
\end{tabular}


para ambas as raças e para os três níveis de $\mathrm{Mg}$, podem ser considerados normais, pois variaram de 1,7 a $2,8 \mathrm{mg} / \mathrm{dL}$, frente às observações do ARC (1980), UNDERWOOD (1981), GEORGEVSKII (1982), que estabeleceram como valores normais de $\mathrm{Mg}$ no soro concentrações de 1,8 a 3,2 mg/dL.
O consumo de água em relação aos diferentes níveis de $\mathrm{Mg}$ e às raças de caprinos em crescimento (Tabela 9) não apresentou diferenças significativas. Dessa forma, a adição de óxido de magnésio nas dietas não teve efeito sobre a ingestão voluntária de água pelos animais.

Tabela 8 - Valor de F e média dos elementos minerais presentes no soro sangüíneo Table 8 - Values of $F$ and mean of the mineral elements present in the blood serum

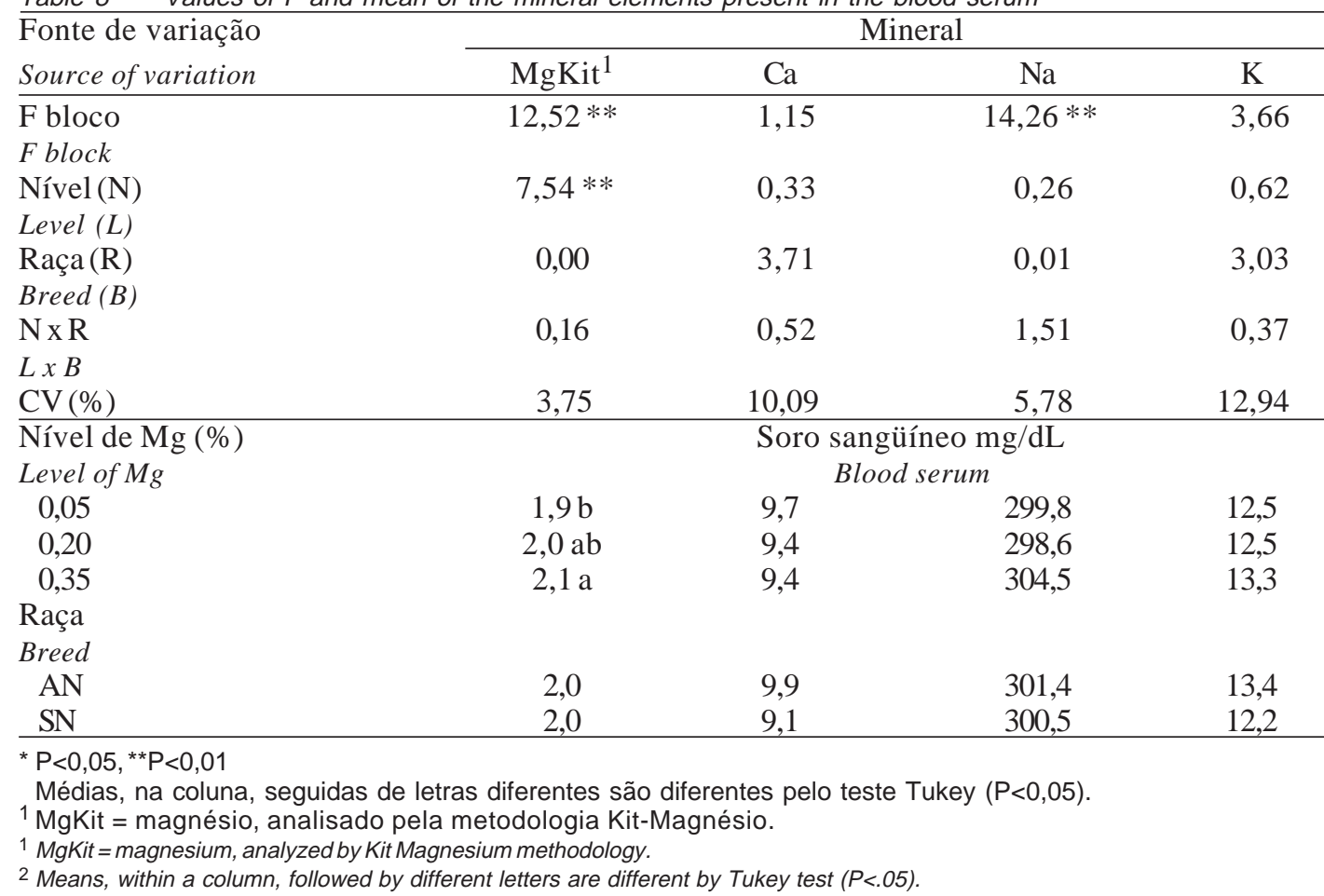

Tabela 9 - Valor de F e média do consumo de água

Table 9 - Value of $F$ and average water ingestion

Fonte de variação Água $\left(\mathrm{L} / \mathrm{PV}^{0,75}\right)$

Source of variation $\quad$ Water $\left(L / L W^{.75}\right)$

F para bloco

0,02

$F$ for block

Nível (N)

Level $(L)$

$\operatorname{Raça}(\mathrm{R})$

0,00

Breed (B)

0,10

$L \times B$

$\mathrm{CV}(\%)$

Nível de $\mathrm{Mg}(\%)$

Level of $\mathrm{Mg}$

0,05

0,13

0,20

0,11

0,35

0,11

Raça

Breed

$\begin{array}{ll}\text { AN } & 0,12 \\ \text { SN } & 0,12\end{array}$




\section{Conclusões}

O aumento nos níveis de $\mathrm{Mg}$ diminuiu os coeficientes de absorção aparente de matéria seca, proteína bruta, cinzas totais, extrativos não-nitrogenados e cálcio para ambas as raças.

A absorção aparente de $\mathrm{Mg}$ foi baixa para o nível de $0,05 \%$ de $\mathrm{Mg}$ dietético.

O coeficiente de absorção real de $\mathrm{Mg}$ para a raça Saanen, obtido a partir das perdas endógenas, foi alto e constante, independente do nível de Mg na dieta, ao passo que a raça Anglonubiana só apresentou valores elevados quando os níveis de $\mathrm{Mg}$ na dieta foram iguais ou superiores a $0,2 \%$ na matéria seca.

As concentrações sangüíneas de $\mathrm{Mg}, \mathrm{Ca}, \mathrm{Na}$ e K não sofreram efeito de raça. Entretanto, os níveis de $\mathrm{Mg}$ no soro aumentaram gradativamente com o aumento do nível do $\mathrm{Mg}$ dietético.

A ingestão ad libitum de água de bebida não apresentou influência de raça ou níveis dietéticos de $\mathrm{Mg}$, com valor médio de $0,12 \mathrm{~L} / \mathrm{kg} \mathrm{PV}^{0,75} /$ dia.

\section{Referências Bibliográficas}

ALLSOP, T.F., ROOK, J.A.F. 1972. Faecal magnesium output and plasma magnesium concentdiet in sheep. Proceedings of the Nutrition Society, 31:65-66.

1979. The effect of diet and blood-plasma magnesium concentdiet on the endogenous faecal loss of magnesium in sheep. J. Agric. Sci., 92:403-408.

AMMERMAN, C.B., CHICCO, C.F. 1968. Availability of inorganic magnesium salts to sheep. J. Anim. Sci., 27(1):288 (Abstracts).

AMMERMAN, C.B., CHICCO, C.F., LOGGINS, P.E. et al. 1972. Availability of different inorganic salts of magnesium to sheep. J. Anim. Sci., 34(1):122-126.

AMMERMAN, C.B., GOODRICH, R.D. 1983. Advances in mineral nutrition in ruminants. J. Anim. Sci., 57(2):519-532.

AGRICULTURAL RESEARCH COUNCIL - ARC. 1980. The nutrient requirements of ruminant livestock. London, Commonwealth Agricultural Boureaux. p.201-211.

BATAGLiA, O.C., TRANI, P.E. 983. Métodos de análise química de plantas. Campinas. Instituto Agronômico (Boletim Técnico 78).

BOIN, C. Exigências de minerais pelas categorias do rebanho bovino e funções desse nutrientes. In: SIMPÓSIO SOBRE NUTRIÇÃO DE BOVINOS, 3, 1985, Piracicaba, FEALQ. Anais... p.15-45, 1985.

CHESTER-JONES, H., FONTENOT, J.P., VEIT, H.P. 1990. Physiological and pathological effects of feeding high levels of magnesium to steers. J. Anim. Sci., 68(12):4400-4413.

CHESTER-JONES, H., FONTENOT, J.P., VEIT, H.P. et al. 1989.The physiological effects of feeding high levels of magnesium to sheep. J. Anim. Sci., 67(4):1070-1081.

CHICCO, C.F., AMMERMAN, C.B., FEASTER, J.P. et al. 1973. Nutritional interrelationships of dietary calcium, phosphorus and magnesium in sheep. J. Anim. Sci., 36(5):986-993.
CONRAD, J.H., McDOWELL, L.R., ELLIS, G.L. et al. 1985. Minerais para ruminantes em pastejo em regões tropicais. Campo Grande, CNPGC-EMBRAPA. 86p.

DAVENPORT, W.C. 1978. Fisiologia do trato digestivo.3.ed. Guanabara-Koogan. p.181-225.

FIELD, A.C. 1961. Studies on magnesium in ruminant. Nutrition 3. Distribution of Mg28 in gastro-intestinal and tissues of sheep. Br. J. Nut., 15:349-355.

GEORGIEVSKII, V.I. 1982. The physiological role of macroelements. In: GEORGIEVSKII, V.I., ANNENKOV, B.N., SAMOKIN, V.I. (Eds.). Mineral nutrition of animal. London, Butterrworths. p.128-137.

GREENE, L.W., FONTENOT, J.P., WEBB JR., K.E. 1983a. Effect of dietary potassium on absorption of magnesium and other macroelements in sheep fed different levels of magnesium. J. Anim. Sci., 56(5):1208-1213.

GREENE, L.W., WEBB JR., K.E., FONTENOT, J.P. 1983 b. Effect of potassium level on site of absorption magnesium and other macroelements in sheep. J.Anim. Sci., 56(5):12141221.

MARTENS, H., RAYSSIGUIER, Y. 1980. In: RUCKEBUSCH, Y., THIVEND, P. (Eds.) Digestive physiology and metabolism in ruminants. AVI, Westport, Connecticut. p.447-466.

MINSON, D. 1990. Forage in ruminant nutrition. San Diego, Academic. p.265-289. Press.

NATIONAL RESEARCH COUNCIL - NRC. 1978. Nutrient requirements of sheep. Washington, D.C. 74p.

NATIONAL RESEARCH COUNCIL - NRC. 1981. Nutrient requeriments of goats. Washington, D.C. 91p.

NATIONAL RESEARCH COUNCIL - NRC. 1989. Nutrient requirements of dairy cattle. Washington, D.C. 176p.

PEELER, H.T. 1972. Biological Availability of Nutrients in Feeds: Availability of major mineral ions. J. Anim. Sci., 35(3):695-712.

REID, R.L., BAKER, B.S., VONA. L.C. 1984. Effects of magnesium sulfate supplementation and fertilization on quality and mineral utilization of timothy hays by sheep. J. Anim. Sci., 59(6):1403-1410.

SAS. 1988. Statistical Analysis of System. Procedures Guide Release Ed. Intitute Inc., Cary NC, USA. 441p.

SCHENEIDER, B., FLATT, W.P. 1975. The evaluation of feeds through digestibility experiments. University of Georgia Press, Athens. 423p.

SILVA, D.J. 1981. Análises de alimentos (métodos químicos e biológicos). Viçosa: UFV. 166p.

TOMAS, M.F.,POTTER,B.J. 1976. The site of magnesium absorption from the ruminant stomach. Br. J. Nut., 36(1):37-45.

WILLIS, J.B. 1961. Determination of calcium and magnesium in urine by atomic absorption spectroscopy. Analytical Chemistry, 33(4):556-559.

WYLIE, M.J., FONTENOT, J.P., GREENE., W.L. 1985. Absorption of magnesium and other macrominerals in sheep infused with potassium in different parts of the digestive tract $J$. Anim. Sci., 61(5):1219-1229.

Recebido em: 04/06/98

Aceito em: 12/04/99 